\title{
Potential drug-drug interactions in hospitalized patients with chronic heart failure and chronic obstructive pulmonary disease
}

\author{
Tina Roblek ${ }^{1}$, Katja Trobec ${ }^{2}$, Ales Mrhar ${ }^{1}$, Mitja Lainscak ${ }^{3,4}$
}

${ }^{1}$ Faculty of Pharmacy, University of Ljubljana, Ljubljana, Slovenia

${ }^{2}$ Hospital Pharmacy, Golnik University Clinic of Pulmonary and Allergic Diseases, Golnik, Slovenia

${ }^{3}$ Applied Cachexia Research, Department of Cardiology, Charité Medical School, Campus Virchow-Klinikum, Berlin, Germany

${ }^{4}$ Division of Cardiology, Golnik University Clinic of Pulmonary and Allergic Diseases, Golnik, Slovenia

Submitted: 19 May 2013

Accepted: 20 September 2013

Arch Med Sci 2014; 10, 5: 920-932

DOI: 10.5114 /aoms.2014.46212

Copyright (c) 2014 Termedia \& Banach

\section{Abstract}

Introduction: Polypharmacy is common in patients with chronic heart failure (HF) and/or chronic obstructive pulmonary disease (COPD), but little is known about the prevalence and significance of drug-drug interactions (DDIs). This study evaluates DDIs in hospitalized patients.

Material and methods: We retrospectively screened medical charts over a 6-month period for diagnosis of chronic HF and/or COPD. Potential DDIs were evaluated using Lexi-Interact software.

Results: Seven hundred and seventy-eight patients were included in the study (median age 75 years, $61 \%$ men). The median number of drugs on admission and discharge was 6 (interquartile range (IQR) 4-9) and 7 (IQR 5-), respectively $(p=0.10)$. We recorded $6.5 \pm 5.7$ potential DDIs per patient on admission and $7.2 \pm 5.6$ on discharge $(p=0.2)$. From admission to discharge, type- $C$ and type-X potential DDIs increased ( $p<0.05$ for both). Type $X$ interactions were rare $(<1 \%)$, with the combination of a $\beta$-blocker and a $\beta_{2}$ agonist being the most common (64\%). There were significantly more type-C and type-D potential DDIs in patients with chronic HF as compared to patients with COPD $(p<0.001)$. Patients with concomitant chronic HF and COPD had more type- $C$ and type- $X$ potential DDIs when compared to those with individual disease $(p<0.005)$. An aldosterone antagonist and ACE inhibitor/ARB were prescribed to $3 \%$ of chronic HF patients with estimated glomerular filtration rate $<30 \mathrm{ml} /\left(\min \times 1.73 \mathrm{~m}^{2}\right)$.

Conclusions: The DDIs are common in patients with chronic HF and/or COPD, but only a few appear to be of clinical significance. The increase in potential DDIs from admission to discharge may reflect better guideline implementation rather than poor clinical practice.

Key words: potential drug-drug interactions, chronic heart failure, chronic obstructive pulmonary disease.

\section{Introduction}

Drug-drug interactions (DDIs) represent a special category of adverse drug reactions (ADRs) in which the effects of one drug influence the effects of the other, thus either limiting effectiveness or inducing toxicity [1]. Overall, $1 \%$ of hospital admissions and $16 \%$ of admissions due to

\section{Corresponding author:} Mitja Lainscak Assoc Prof., MD, PhD, FESC

Division of Cardiology Golnik University Clinic of Respiratory and Allergic Diseases Golnik 36

SI-4204 Golnik, Slovenia Phone: +38642569483 Fax: +38642569117 E-mail: mitja.lainscak@guest. arnes.si 
ADRs can be attributed to DDIs [2]. A higher number of DDIs is also significantly associated with longer hospitalization and higher treatment costs $[1,3,4]$. The probability of DDIs increases with the number of drugs prescribed to patients [5-9]. The incidence ranges from $13 \%$ for two drugs prescribed to $82 \%$ for seven or more drugs [10].

There is a lack of studies on DDI incidence in patients with chronic heart failure (HF) and/or chronic obstructive pulmonary disease (COPD) and their clinical relevance. Polypharmacy is common in patients with these two conditions, but could be guideline-driven [11-13]. Comorbidity leads to prescribing more drugs on a regular basis if individual guidelines are implemented as appropriate. The complexity of the treatment regimen increases the probability of DDIs and prolongs hospitalization [1, 3-9]. A recent study that included 400 patients with chronic HF (median age 79 ; $55.5 \%$ men) reported a median of two major interactions on admission and three at discharge [8]. In general, the most common combinations of medications in which potential DDIs occurred during hospitalization were a combination of potassium-sparing diuretics and angiotensin-converting enzyme (ACE) inhibitors or angiotensin receptor blockers (ARB), and, second, a combination of aspirin and non-selective $\beta$-blockers in patients concomitantly treated with a $\beta$, agonist $[1,7,8,14]$. To the best of our knowledge, no study has yet investigated DDIs in patients with COPD.

With little information at hand, we designed this study to evaluate the prevalence of DDIs at hospital admission and at discharge in patients with chronic HF and/or COPD. We also assessed the type of DDIs according to accepted classifications. In addition, we specifically analyzed interactions of potential clinical relevance according to estimated renal function.

\section{Material and methods}

\section{Study design and patients}

This was a retrospective study that included all consecutive patients who were discharged or died in the 6-month period from January 2011 to June 2011 with any discharge diagnosis of chronic HF or COPD at the Golnik University Clinic of Pulmonary and Allergic Diseases, Slovenia. The National Ethics Committee approved the protocol of this study (no. 77/11/11).

Patient discharge records were screened and selected if the diagnosis was coded chronic HF and/ or COPD according to International Classification of Diseases 10 (ICD 10). This included diagnosis of chronic HF I50.0-150.9, I42.0-142.9, I11.0-I11.9, and COPD J44.0-J44.9. We excluded patients who had fewer than two medications prescribed on admission or discharge or both, who died during their hospital stay, or who had incomplete medical records regarding the medication prescribed either on admission or at discharge (Figure 1).

\section{Data collection}

The following data were extracted from medical documentation: patient characteristics (age, sex, concomitant diseases, heart rate, blood pressure), laboratory test results (serum creatinine concentration, hemoglobin concentration), number of diagnoses per patient, and length of hospital stay. Data about medication prescribed on admission and at discharge were retrieved from the discharge letter.

Several databases that describe and evaluate potential DDIs have been developed. The most common are the British National Formulary, Drug Interaction Facts, Drug-reax, ePocrates, Lexi-Interact, Pharmavista, and Stockley's Drug Interactions. The sensitivity and precision of these were evaluated taking Stockley's Drug Interactions database as the gold standard. The aim was to assess which database detects the most clinically significant potential DDIs and avoids reporting clinically non-significant interactions. None of the databases represented a completely reliable DDI

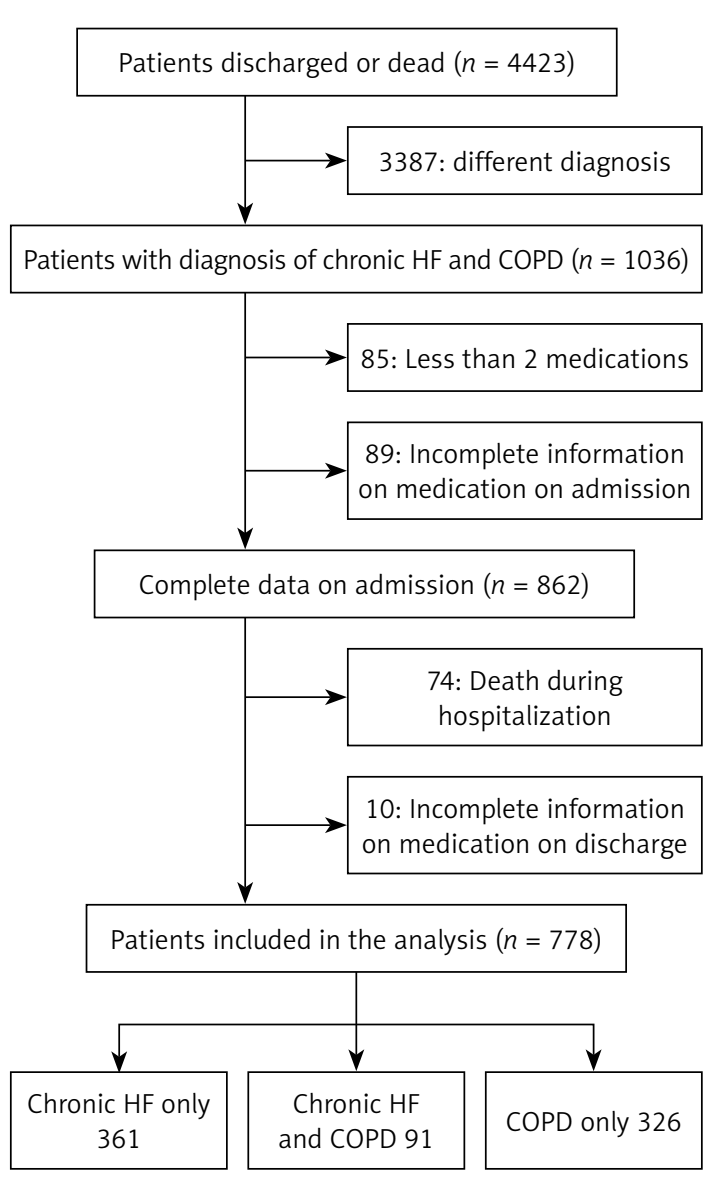

Figure 1. Patient selection 
Table I. Classification of DDIs according to their clinical relevance

\begin{tabular}{|lll|}
\hline Risk rating & \multicolumn{1}{|c|}{ Action } & \multicolumn{1}{c|}{ Description } \\
\hline A & No known interaction & $\begin{array}{l}\text { Data have not demonstrated either pharmacodynamic or pharmacokinetic } \\
\text { interactions between the specified agents. }\end{array}$ \\
\hline B & No action needed & $\begin{array}{l}\text { Data demonstrate that the specified agents may interact with each other, } \\
\text { but there is little to no evidence of clinical concern resulting from their } \\
\text { concomitant use. }\end{array}$ \\
\hline C & Monitor therapy & $\begin{array}{l}\text { Data demonstrate that the specified agents may interact with each other } \\
\text { in a clinically significant manner. The benefits of concomitant use of these } \\
\text { two medications usually outweigh the risks. An appropriate monitoring } \\
\text { plan should be implemented to identify potential negative effects. Dosage } \\
\text { adjustments of one or both agents may be needed in a minority of patients. }\end{array}$ \\
\hline D & $\begin{array}{l}\text { Data demonstrate that the two medications may interact with each other } \\
\text { in a clinically significant manner. A patient-specific assessment must be } \\
\text { conducted to determine whether the benefits of concomitant therapy } \\
\text { outweigh the risks. Specific actions must be taken in order to realize the } \\
\text { benefits and/or minimize the toxicity resulting from concomitant use of the } \\
\text { agents. These actions may include aggressive monitoring, empiric dosage } \\
\text { changes, or choosing alternative agents. }\end{array}$ \\
\hline X & $\begin{array}{l}\text { Data demonstrate that the specified agents may interact with each other } \\
\text { in a clinically significant manner. The risks associated with concomitant use } \\
\text { of these agents usually outweigh the benefits. These agents are generally } \\
\text { considered contraindicated. }\end{array}$ \\
\hline
\end{tabular}

reporting system in terms of sensitivity and specificity, but Lexi-Interact showed the best results in precision analysis despite a lower positive predictive value, which means that it also detects clinically non-significant potential DDIs. Pharmavista had lower sensitivity but a higher positive predictive value [15].

Our study used the Lexi-Interact database (available on UpToDate, 2012, release 20.8-C20.20) to evaluate patients' medication schemes for potential DDIs. The system provides information about the risk of DDI, and pharmacokinetic and pharmacodynamic effects and mechanisms of DDIs. It gives recommendations about managing DDIs and provides referenced literature. The software identified and classified DDIs according to their clinical relevance in the categories which are presented in Table I.

We analyzed type- $C$, - $D$, and $-X$ potential interactions because they were considered clinically significant in previous studies [16-18]. We specifically analyzed combinations of drugs (ACE inhibitors/ARB and/or aldosterone antagonists) in patients stratified according to estimated renal function. Renal function was estimated from serum creatinine concentration using the abbreviated Modification of Diet in Renal Disease (MDRD) equation [19].

Potential DDIs between drugs that were not listed in Lexi-Interact were evaluated by a panel of experts. The ML, TR, and KT reviewed drug pairs and evaluated DDIs. In the case of disagreement, the fourth member (AM) estimated the severity of DDIs. Evaluation was based on the drugs' product characteristics leaflets and by comparison to drugs of similar pharmacokinetic and/or pharmacodynamic profiles that are included in the Lexi-Interact database. Assessment included possible pharmacokinetic and pharmacodynamic interactions that were categorized into three levels of clinical significance, C, D, and X, in the same manner as in Lexi-Interact. These are presented in Table II.

\section{Statistical analysis}

Standard descriptive statistics was used to describe patient demographics. Mean and standard deviation or median and interquartile range were calculated for age, length of hospital stay, number of diagnoses, and number of drugs prescribed. Proportions were calculated for categorical data, which included sex and number of drugs on admission and discharge. The percentage of patients receiving cardiovascular and/or respiratory drugs of different pharmacologic classes was evaluated for patients with chronic HF, COPD, or both.

Normal distribution was evaluated with the Kolmogorov-Smirnov test. The average number of drugs and potential DDIs of different level per patient on admission and discharge were compared with a paired sample $t$-test. McNemar's test was used to compare the number of patients with at least one potential DDI of level C, D, or X on admission versus discharge. An independent $t$-test was used to compare the mean number of potential interactions of clinical significance level C, D, and X in the groups of patients with COPD or chronic HF, and patients with both medical conditions. Linear regression was used to calculate the association 
Table II. Potential DDIs assessed by panel of experts based on pharmacokinetic and pharmacodynamic properties

\begin{tabular}{|c|c|c|}
\hline Drug-drug interaction & Clinical significance level & Description of DDI \\
\hline Moxonidine-zolpidem & C & Central nervous system depression \\
\hline Biperiden-zuclopentixol & C & $\begin{array}{l}\text { Enhanced anticholinergic effects, } \\
\text { higher risk of tardive dyskinesia }\end{array}$ \\
\hline Biperiden-haloperidol & C & $\begin{array}{l}\text { Enhanced anticholinergic effects, } \\
\text { higher risk of tardive dyskinesia }\end{array}$ \\
\hline Biperiden-ipratropium, tiotropium & C & Enhanced anticholinergic effects \\
\hline Biperiden-clozapine & C & $\begin{array}{l}\text { Enhanced anticholinergic effects, } \\
\text { higher risk of tardive dyskinesia }\end{array}$ \\
\hline Piracetam-warfarin & C & $\begin{array}{l}\text { Enhanced effect on platelet aggregation, } \\
\text { fibrinogen and von Willebrand factor }\end{array}$ \\
\hline Tianeptine-benzodiazepine & C & Central nervous system depression \\
\hline Tianeptine-fentanyl & C & Central nervous system depression \\
\hline Tianeptine-levetiracetam & $\mathrm{C}$ & Central nervous system depression \\
\hline Tianeptine-risperidone & C & Central nervous system depression \\
\hline Tianeptine-zolpidem & C & Central nervous system depression \\
\hline Sulpiride-ACE inhibitors & C & Enhanced hypotensive effect \\
\hline $\begin{array}{l}\text { Sulpiride-angiotensin receptor } \\
\text { blockers }\end{array}$ & C & Enhanced hypotensive effect \\
\hline Sulpiride- $\beta$-blockers & C & Enhanced hypotensive effect \\
\hline Sulpiride-diuretics & C & Electrolyte imbalance \\
\hline Sulpiride-calcium channel blockers & C & Enhanced hypotensive effect \\
\hline Sulpiride-benzodiazepines & C & Central nervous system depression \\
\hline Sulpiride-mianserin & $\mathrm{C}$ & Central nervous system depression \\
\hline Sulpiride-nitroglycerin & $\mathrm{C}$ & Enhanced hypotensive effect \\
\hline Sulpiride-tramadol & $\mathrm{D}$ & Enhanced risk of seizures \\
\hline Thiethylperazine-tramadol & C & Central nervous system depression \\
\hline
\end{tabular}

between number of potential DDIs of significance level $C, D$, and $X$ and the number of diagnoses, number of drugs, and the length of hospital stay.

For all of the tests, a $p$ value $<0.05$ was considered statistically significant. Data were analyzed using Statistical Package for the Social Sciences (SPSS) 17.0 software.

\section{Results}

\section{Patient characteristics}

We screened 4423 discharge letters and identified 1036 potentially eligible patients. Exclusion criteria were met in 258 patients: 74 had incomplete documentation on their medication on admission, 10 had incomplete documentation on their medication at discharge, 15 had incomplete documentation on their medication on admission and at discharge, 85 were prescribed fewer than two medications, and 74 died during their hospi- tal stay. Thus, 778 patients were included in the study, of whom 361 had a diagnosis of chronic HF and 326 had COPD. Both diagnoses were present in 91 patients (Figure 1). The characteristics of the study population are presented in Table III.

The median age was 75 years (interquartile range (IQR) 67-82); 61\% were men. The median number of drugs on admission was six (IQR 4-9) and at discharge seven (IQR 5-9) $(p=0.10)$.

Table IV presents the number of patients with chronic HF and COPD receiving drugs from the most common pharmacological classes of cardiovascular and respiratory drugs on admission and at discharge.

Figure 2 compares the proportions of all patients (groups of chronic HF patients, COPD patients, and patients with both diagnoses are presented in Figures 3-5) with various numbers of drugs prescribed on admission and at discharge. In patients with only chronic HF or only COPD, 
Table III. Patient characteristics and laboratory test results, represented as median and interquartile range and number of patients (percentage) with diagnosis of chronic HF and/or COPD and concomitant diseases

\begin{tabular}{|c|c|c|c|c|}
\hline Study population & $\begin{array}{c}\text { All patients } \\
(n=778) \\
\text { Mean } \pm \text { SD/n (\%) }\end{array}$ & $\begin{array}{c}\text { Patients } \\
\text { with chronic HF } \\
(n=361) \\
\text { Mean } \pm \text { SD/n (\%) }\end{array}$ & $\begin{array}{c}\text { Patients } \\
\text { with COPD } \\
(n=326) \\
\text { Mean } \pm \text { SD } / n(\%)\end{array}$ & $\begin{array}{c}\text { Patients } \\
\text { with COPD } \\
\text { and chronic HF } \\
(n=91) \\
\text { Mean } \pm \text { SD/n (\%) }\end{array}$ \\
\hline Men & $474(61)$ & $185(51)$ & $224(69)$ & $65(71)$ \\
\hline Age [years] & $74 \pm 10$ & $77 \pm 9$ & $70 \pm 10$ & $79 \pm 7$ \\
\hline Length of hospital stay [days] & $11 \pm 10$ & $11 \pm 10$ & $10 \pm 10$ & $11 \pm 8$ \\
\hline Number of diagnoses & $6 \pm 2$ & $6 \pm 2$ & $5 \pm 2$ & $7 \pm 2$ \\
\hline \multicolumn{5}{|l|}{ Laboratory data: } \\
\hline Systolic blood pressure [mm Hg] & $142 \pm 24(n=643)$ & $143 \pm 25(n=312)$ & $144 \pm 22(n=255)$ & $145 \pm 26(n=76)$ \\
\hline Diastolic blood pressure [mm Hg] & $80 \pm 14(n=643)$ & $80 \pm 14(n=312)$ & $80 \pm 12(n=255)$ & $80 \pm 14(n=76)$ \\
\hline Heart rate $[\mathrm{bpm}]$ & $90 \pm 21(n=719)$ & $88 \pm 21(n=341)$ & $92 \pm 12(n=295)$ & $92 \pm 22(n=83)$ \\
\hline Hemoglobin $[g / l]$ & $132 \pm 22(n=639)$ & $126 \pm 22(n=303)$ & $138 \pm 21(n=260)$ & $132 \pm 22(n=77)$ \\
\hline $\mathrm{eGFR}\left[\mathrm{ml} /\left(\min \times 1.73 \mathrm{~m}^{2}\right)\right]$ & $72 \pm 128(n=607)$ & $65 \pm 23(n=301)$ & $95 \pm 206(n=225)$ & $70 \pm 31(n=77)$ \\
\hline Creatinine $[\mu \mathrm{mol} / \mathrm{l}]$ & $103 \pm 52(n=607)$ & $116 \pm 61(n=301)$ & $86 \pm 34(n=225)$ & $100 \pm 44(n=77)$ \\
\hline \multicolumn{5}{|l|}{ Concomitant diseases: } \\
\hline Hypertension & $350(45)$ & $179(50)$ & $130(40)$ & $41(45)$ \\
\hline Diabetes & $169(22)$ & $114(32)$ & $32(10)$ & $23(25)$ \\
\hline Atrial fibrillation & $228(29)$ & $162(45)$ & $31(10)$ & $23(25)$ \\
\hline Ischemic heart disease & $51(7)$ & $27(7)$ & $18(6)$ & $6(7)$ \\
\hline Dyslipidemia & $35(5)$ & $20(6)$ & $12(4)$ & $3(3)$ \\
\hline
\end{tabular}

the median number of drugs on admission was six and did not change during hospitalization. Patients with chronic HF and COPD received a median number of eight drugs per patient on admission and discharge, which was higher than in patients with chronic HF or COPD ( $p<0.05$ for both).

The median number of potential DDIs on admission was five (IQR 2-10) per patient versus six $($ IQR 3-10) $(p=0.2)$ at discharge. Out of 5,085 potential DDIs identified on admission, 4,697 were classified with clinical significance level C, 335 with level D, and 33 with level X. During hospitalization, the number of potential DDIs increased to 5,604: 5,207 at level C, 352 at level D, and 45 at level $X$. The number of patients with at least one DDI on admission and at discharge and the total number of DDIs of significance level C, D, and X are presented in Table $\mathrm{V}$. There were significantly more patients with at least one potential DDI of clinical significance level $C$ and $X$ at discharge than on admission $(p=0.01)$.

The most common drug combinations flagged with level C, D, and X potential DDI at hospital discharge are presented in Tables VI-VIII, respectively. We identified 485 different drug combi- nations with potential DDIs; 373 of these were DDIs of clinical significance C (Table VI). The most common were between a loop diuretic and a $\beta_{2}$ receptor agonist (6.6\% of cases), followed by a combination of two $\beta_{2}$ receptor agonists (6\%). At hospital discharge, 98 level-D interactions were identified (Table VII), the most common being those between a $\beta$-blocker and an $\alpha$ antagonist (12.3\%), followed by cases of calcium carbonate and bisphosphonate combination (7.1\%) and ACE inhibitor and allopurinol combination (6\%).

Forty-five cases of potential DDIs of clinical significance $X$ at hospital discharge, which included 14 different drug combinations, are presented in Table VIII. In the majority of cases (63\%), there was an interaction between a non-selective $\beta$-blocker and a $\beta_{2}$ agonist. The most common drugs involved in potential DDIs of clinical significance level $X$ were quetiapine (4 cases), clozapine ( 2 cases), and haloperidol (2 cases). Out of 778 patients, 14 were prescribed quetiapine, four clozapine, and 16 haloperidol.

Patients with chronic HF had significantly more level-C and level-D interactions when compared to patients with COPD: $8.18 \pm 5.24$ vs. $4.68 \pm 4.43$ ( $p<$ 
Table IV. Number (percentage) of patients with chronic HF and COPD receiving the most frequently prescribed cardiovascular drugs on admission and at discharge

\begin{tabular}{|c|c|c|}
\hline Variable & $\begin{array}{c}N(\%) \text { on } \\
\text { admission }\end{array}$ & $\begin{array}{l}N(\%) \text { at } \\
\text { discharge }\end{array}$ \\
\hline \multicolumn{3}{|l|}{ Patients with chronic HF $(n=361)$ : } \\
\hline Diuretics & $246(68)$ & $228(80)$ \\
\hline $\begin{array}{l}\text { Angiotensin-converting } \\
\text { enzyme inhibitors }\end{array}$ & $225(62)$ & $228(63)$ \\
\hline$\beta$-Blockers & $195(54)$ & $207(57)$ \\
\hline Aspirin & $135(37)$ & $145(40)$ \\
\hline Warfarin & $109(30)$ & $119(33)$ \\
\hline Calcium channel blockers & $97(27)$ & $94(26)$ \\
\hline Digoxin & $64(18)$ & $87(24)$ \\
\hline Aldosterone antagonist & $62(17)$ & $76(21)$ \\
\hline Angiotensin receptor blockers & $57(16)$ & $60(16)$ \\
\hline$\alpha$-Receptor antagonist & $30(8)$ & $27(7)$ \\
\hline \multicolumn{3}{|l|}{ Patients with COPD $(n=326)$} \\
\hline $\begin{array}{l}\text { Inhaled corticosteroids/ } \\
\text { long-acting } \beta_{2} \text { agonist }\end{array}$ & $190(58)$ & $185(56)$ \\
\hline Tiotropium & $180(55)$ & $192(59)$ \\
\hline $\begin{array}{l}\text { Ipratropium/short-acting } \beta_{2} \\
\text { agonist }\end{array}$ & $134(41)$ & $185(56)$ \\
\hline Short-acting $\beta_{2}$ agonists & $111(34)$ & $90(28)$ \\
\hline Theophylline derivatives & $81(25)$ & $80(25)$ \\
\hline Long-acting $\beta_{2}$ agonists & $25(8)$ & $26(8)$ \\
\hline Methylprednisolone & $17(5)$ & $17(5)$ \\
\hline Inhaled corticosteroids & $11(3)$ & $10(3)$ \\
\hline \multicolumn{3}{|c|}{ Patients with chronic HF and COPD $(n=91)$} \\
\hline Diuretics & $63(69)$ & $75(82)$ \\
\hline $\begin{array}{l}\text { Angiotensin-converting } \\
\text { enzyme inhibitors }\end{array}$ & $60(66)$ & $58(64)$ \\
\hline$\beta$-Blockers & $35(38)$ & $37(41)$ \\
\hline Aspirin & $28(31)$ & $31(34)$ \\
\hline Warfarin & $23(25)$ & $21(23)$ \\
\hline Calcium channel blockers & $21(23)$ & $22(24)$ \\
\hline Digoxin & $19(21)$ & $27(30)$ \\
\hline Aldosterone antagonist & $8(9)$ & $8(9)$ \\
\hline Angiotensin receptor blockers & $9(10)$ & $8(9)$ \\
\hline$\alpha$-Receptor antagonist & $9(10)$ & $6(6)$ \\
\hline $\begin{array}{l}\text { Inhaled corticosteroids/ } \\
\text { Ing-acting } \beta_{2} \text { agonist }\end{array}$ & $45(49)$ & $48(53)$ \\
\hline Tiotropium & $38(41)$ & $36(40)$ \\
\hline $\begin{array}{l}\text { Ipratropium/short-acting } \beta_{2} \\
\text { agonist }\end{array}$ & $50(55)$ & $58(64)$ \\
\hline Short-acting $\beta_{2}$ agonists & $24(26)$ & $16(18)$ \\
\hline Theophylline derivatives & $101(24)$ & $36(40)$ \\
\hline Long-acting $\beta_{2}$ agonists & $7(8)$ & $10(11)$ \\
\hline Methylprednisolone & $7(8)$ & $8(10)$ \\
\hline Inhaled corticosteroids & $2(2)$ & $3(3)$ \\
\hline
\end{tabular}

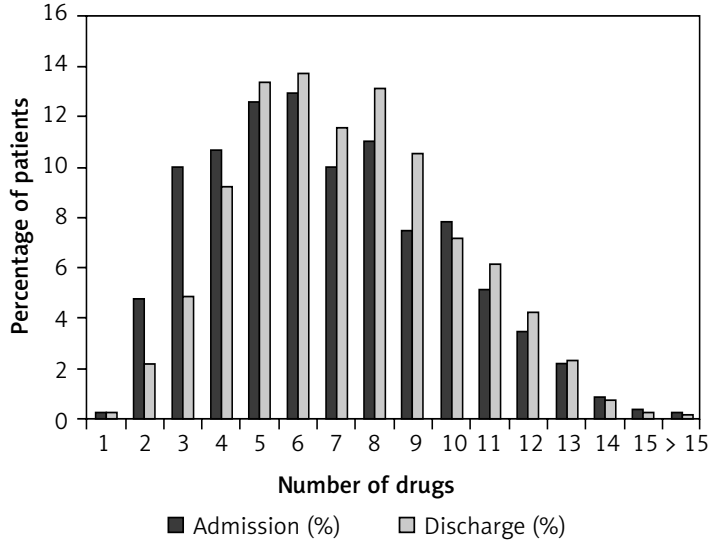

Figure 2. Proportion of all patients $(n=778)$ and the number of drugs on admission and on discharge

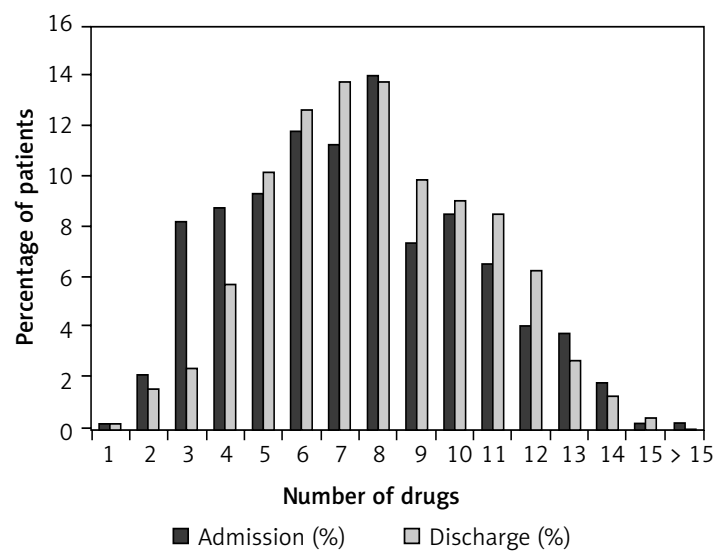

Figure 3. Proportion of patients with chronic HF $(n=361)$ and number of drugs on admission and at discharge

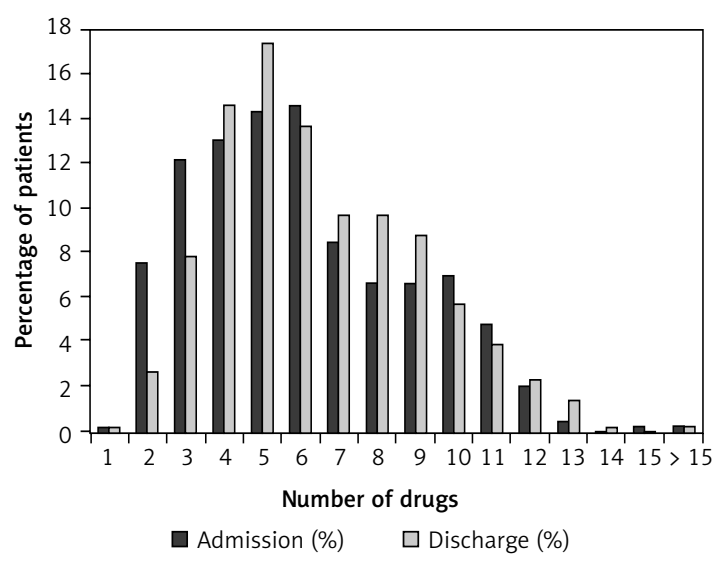

Figure 4. Proportion of patients with COPD $(n=326)$ and number of drugs on admission and at discharge

$0.001)$ and $0.55 \pm 0.88$ vs. $0.33 \pm 0.71(p<0.001)$, respectively. In 91 patients with chronic HF and COPD, there were significantly more potential DDIs of clinical significance level C $(10.25 \pm 6.21)$ when compared to other patients $(6.25 \pm 4.88)(p<0.001)$. There was also a significantly higher number of 


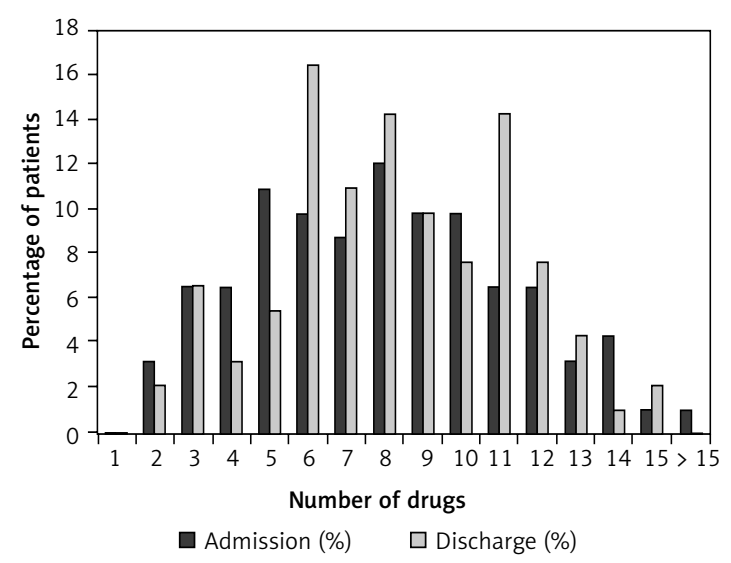

Figure 5. Proportion of patients with COPD and chronic HF ( $n=91)$ and number of drugs on admission and at discharge

potential DDIs of clinical significance level $X$ in patients with both medical conditions compared to patients with only chronic HF or COPD, $0.14 \pm 0.25$ vs. $0.05 \pm 0.51$, respectively $(p=0.003)$. Figure 6 presents the number of potential DDIs at level C, D, and $X$ per patient on admission and at discharge in patients with COPD only, chronic HF only, and concomitant COPD and chronic HF.

There was an association between the number of diagnoses and the number of potential DDIs of significance level C $\left(r^{2}=0.148, p<0.001\right)$, D $\left(r^{2}=\right.$ $0.148, p<0.001)$, and $X\left(r^{2}=0.035, p<0.001\right)$. The same association was observed with the number of drugs (Table IX).

For the group of patients with chronic HF $(n=452)$, we evaluated a possible interaction between ACE inhibitor and/or ARB with spironolactone according to the estimated renal function. eGFR was available for 379 (84\%), and 77 of these had concomitant COPD. Patients were classified into three groups: 36 patients had eGFR $\leq 30 \mathrm{ml} /$ $\left(\mathrm{min} \times 1.73 \mathrm{~m}^{2}\right), 176$ between 30 and $59 \mathrm{ml} /(\mathrm{min}$ $\left.\times 1.73 \mathrm{~m}^{2}\right)$, and $167 \geq 60 \mathrm{ml} /\left(\min \times 1.73 \mathrm{~m}^{2}\right)$. Three percent of patients with eGFR $\leq 30 \mathrm{ml}$ $\left(\mathrm{min} \times 1.73 \mathrm{~m}^{2}\right)$ were prescribed an ACE inhibitor and/or ARB and spironolactone, $72 \%$ only an ACE inhibitor or $A R B$, and $3 \%$ only spironolactone at discharge. A combination of ACE inhibitor and/or $A R B$ and spironolactone was prescribed in $22 \%$ of patients with eGFR between 30 and $59 \mathrm{ml} /(\mathrm{min} \times$ $1.73 \mathrm{~m}^{2}$ ) and in $13 \%$ of patients with eGFR $\geq 60 \mathrm{ml}$ $\left(\mathrm{min} \times 1.73 \mathrm{~m}^{2}\right)$ at discharge (Figure 7$)$. Only 3 out of 452 patients were concomitantly prescribed an ACE inhibitor and an ARB. None of these had reduced renal function.

\section{Discussion}

This is the first study to report on potential DDIs in patients with chronic HF and/or COPD. The DDIs per patient increased from admission to discharge and were more common in patients with concomitant chronic HF and COPD. The most common type-X potential DDI was a combination of $\beta$-blocker and $\beta_{2}$ agonist, which may reflect better guideline implementation rather than poor clinical practice. In many patients with impaired renal function, greater caution regarding renin-angiotensin-aldosterone antagonist use should be considered.

The study population reflects the patient population from daily clinical practice and the population included in other studies [20-22]. Twenty percent of patients with chronic HF had concomitant COPD, which is similar to the proportion of patients included in the study assessing the prevalence of these two conditions [22].

In our study, only $26 \%$ of discharged COPD patients were prescribed a short-acting $\beta_{2}$ agonist (SABA), 59\% a combination of SABA and ipratropium, and $28 \%$ theophylline, which is not in line with other studies conducted on this population

Table V. Number of patients with at least one potential interaction of significance level C, D, or X on admission and at discharge

\begin{tabular}{|lccc|}
\hline Type of interaction & Hospital admission & Hospital discharge & $\begin{array}{c}\text { Value of } p \\
\text { (McNemar's test) }\end{array}$ \\
\hline \begin{tabular}{l} 
Total number of potential interactions: \\
\hline C
\end{tabular} & 4,697 & 5,027 \\
\hline D & 335 & 352 \\
\hline X & 33 & 45 \\
\hline All interactions & 5,085 & 5,604 & \\
\hline Number of patients (\%) with at least one interaction: & & 0.01 \\
\hline C & $714(91.7)$ & $735(94.5)$ & 0.39 \\
\hline D & $223(28.7)$ & $38(5.0)$ & 0.08 \\
\hline X & $27(3.4)$ & $(30.2)$ & \\
\hline
\end{tabular}


Table VI. The most common combinations of DDIs of clinical significance level C on hospital discharge

\begin{tabular}{|c|c|c|}
\hline Drug-drug interaction & $N(\%)$ & Description \\
\hline \multicolumn{3}{|c|}{ Total DDIs of clinical significance level $C$ at discharge $n=5,027$} \\
\hline $\begin{array}{l}\text { Loop diuretic- } \beta_{2} \text { receptor } \\
\text { agonist }\end{array}$ & $330(6.6)$ & $\begin{array}{l}\beta_{2} \text { receptor agonists may enhance the hypokalemic effect of loop } \\
\text { diuretics. }\end{array}$ \\
\hline $\begin{array}{l}\beta_{2} \text { Receptor agonist }-\beta_{2} \\
\text { receptor agonist }\end{array}$ & $304(6.0)$ & $\begin{array}{l}\text { Sympathomimetics may enhance the adverse/toxic effect of other } \\
\text { sympathomimetics. }\end{array}$ \\
\hline$\beta$-Blocker-diuretic & $297(5.9)$ & $\begin{array}{l}\text { Antihypertensives may enhance the hypotensive effect of other } \\
\text { antihypertensives. }\end{array}$ \\
\hline ACE inhibitor-loop diuretic & $280(5.6)$ & $\begin{array}{l}\text { Loop diuretics may enhance the hypotensive effect of ACE inhibitors, } \\
\text { specifically, postural hypotension which can accompany ACE inhibitor } \\
\text { initiation. Loop diuretics may enhance the nephrotoxic effect of ACE } \\
\text { inhibitors. }\end{array}$ \\
\hline$\beta$-Blocker-ACE inhibitor & $201(4.0)$ & $\begin{array}{l}\text { Antihypertensives may enhance the hypotensive effect of other } \\
\text { antihypertensives. }\end{array}$ \\
\hline $\begin{array}{l}\beta_{2} \text { Receptor agonist- } \\
\text { theophylline }\end{array}$ & $193(3.8)$ & $\begin{array}{l}\text { Sympathomimetics may enhance the adverse/toxic effect of other } \\
\text { sympathomimetics. }\end{array}$ \\
\hline ACE inhibitor-aspirin & $174(3.5)$ & $\begin{array}{l}\text { Salicylates may diminish the antihypertensive effect of ACE inhibitors. } \\
\text { They may also diminish other beneficial pharmacodynamic effects } \\
\text { desired for the treatment of CHF. The effects are likely dose-related. }\end{array}$ \\
\hline Diuretic-corticosteroid & $167(3.3)$ & $\begin{array}{l}\text { Corticosteroids (orally inhaled) may enhance the hypokalemic effect } \\
\text { of loop diuretics. }\end{array}$ \\
\hline Diuretic-aspirin & $163(3.2)$ & $\begin{array}{l}\text { Salicylates may diminish the diuretic effect of loop diuretics. } \\
\text { Loop diuretics may increase the serum concentration of salicylates. }\end{array}$ \\
\hline $\begin{array}{l}\beta \text {-Blocker (nebivolol, } \\
\text { bisoprolol)- } \beta_{2} \text { receptor } \\
\text { agonist }\end{array}$ & $143(2.8)$ & $\begin{array}{l}\beta \text {-Blockers ( } \beta_{1} \text { selective) may diminish the bronchodilatory effect } \\
\text { of } \beta_{2} \text { receptor agonists - of particular concern with nonselective } \\
\beta \text {-blockers or higher doses of } \beta_{1} \text { selective } \beta \text {-blockers. }\end{array}$ \\
\hline $\begin{array}{l}\text { Calcium channel blocker- } \\
\text { diuretic }\end{array}$ & $128(2.5)$ & $\begin{array}{l}\text { Antihypertensives may enhance the hypotensive effect of other } \\
\text { antihypertensives. }\end{array}$ \\
\hline Tiotropium-ipratropium & $124(2.4)$ & $\begin{array}{l}\text { Anticholinergics may enhance the adverse/toxic effect of other } \\
\text { anticholinergics. }\end{array}$ \\
\hline $\begin{array}{l}\text { Statin-proton pump } \\
\text { inhibitor }\end{array}$ & $107(2.1)$ & $\begin{array}{l}\text { Proton pump inhibitors may increase the serum concentration } \\
\text { of } \mathrm{HMG}-\mathrm{CoA} \text { reductase inhibitors. }\end{array}$ \\
\hline Loop diuretic-digoxin & $90(1.8)$ & $\begin{array}{l}\text { Loop diuretics may enhance the adverse/toxic effect of cardiac } \\
\text { glycosides, by increasing the risk of hypokalemia. }\end{array}$ \\
\hline
\end{tabular}

in Slovenia. A study on COPD patients in the same hospital setting showed that $91 \%$ of patients were prescribed a SABA, $64 \%$ a combination of SABA and ipratropium, and $64 \%$ theophylline [21]. This shows poor adherence to treatment guidelines in our setting. In the cohort of patients with chronic $\mathrm{HF}, 81 \%$ of patients were prescribed a diuretic, $62 \%$ an ACE inhibitor, $16 \%$ an ARB, and $57 \%$ a $\beta$-blocker. These numbers did not increase markedly during the hospital stay, although this would be in accordance with treatment guidelines for chronic HF. In another study that included patients with chronic HF and concomitant COPD, $98 \%$ were prescribed furosemide, $77 \%$ an ACE inhibitor/ARB, and only $12 \%$ a $\beta$-blocker [22].

The number of drugs prescribed per patient did not significantly increase from admission to discharge, and thus neither did the average number of potential DDIs. Similar findings were observed in a Swiss study that was conducted on a med- ical ward and showed that on average patients were taking four medications on admission, 11 during hospitalization, and six at hospital discharge. Consequently, the frequency of potential DDIs was $30 \%$ on admission, $56 \%$ during hospitalization, and $31 \%$ at discharge. Three hundred and ninety-six patients out of 697 (56.8\%) had at least one potential DDI at discharge, $47 \%$ of those due to treatment change during the hospital stay [7]. Despite no change in the number of all potential DDIs per patient, the number of type- $C$ and type- $X$ interactions increased from admission to discharge (Table V). Furthermore, a comparison between groups (Figure 6) showed that the number of level-C and level- $X$ interactions significantly increased only in patients with concomitant chronic $\mathrm{HF}$ and COPD, but not in patients with chronic $\mathrm{HF}$ and COPD only. In the case of type- $X$ interactions, this may be explained by the addition of a $\beta_{2}$ agonist for the treatment of COPD in patients already 
Table VII. The most common combinations of DDIs of clinical significance level D on hospital discharge

\begin{tabular}{|c|c|c|}
\hline Drug-drug interaction & $N(\%)$ & Description \\
\hline \multicolumn{3}{|c|}{ Total DDIs of clinical significance level D at discharge $n=352$} \\
\hline $\begin{array}{l}\beta \text {-Blocker- } \alpha \text { receptor } \\
\text { antagonist }\end{array}$ & $43(12.2)$ & $\begin{array}{l}\beta \text {-Blockers may enhance the orthostatic hypotensive effect } \\
\text { of } \alpha_{1} \text {-blockers. }\end{array}$ \\
\hline $\begin{array}{l}\text { Calcium carbonate- } \\
\text { bisphosphonates }\end{array}$ & $25(7.1)$ & $\begin{array}{l}\text { Calcium salts may reduce the serum concentration of } \\
\text { bisphosphonate derivatives. }\end{array}$ \\
\hline ACE inhibitor-allopurinol & $21(6.0)$ & $\begin{array}{l}\text { ACE inhibitors may enhance the potential for allergic or } \\
\text { hypersensitivity reactions to allopurinol. }\end{array}$ \\
\hline $\begin{array}{l}\text { ACE inhibitor (except } \\
\text { ramipril)-calcium carbonate }\end{array}$ & $20(5.7)$ & Antacids may reduce the serum concentration of ACE inhibitors. \\
\hline Levothyroxine-warfarin & $14(4.0)$ & $\begin{array}{l}\text { Thyroid products may enhance the anticoagulant effect of vitamin } \mathrm{K} \\
\text { antagonists. }\end{array}$ \\
\hline $\begin{array}{l}\text { Methylprednisolone-calcium } \\
\text { carbonate }\end{array}$ & $13(3.7)$ & Antacids may reduce the bioavailability of corticosteroids (oral). \\
\hline NSAIDs-loop diuretic & $13(3.7)$ & $\begin{array}{l}\text { Nonsteroidal anti-inflammatory agents may diminish the diuretic } \\
\text { effect of loop diuretics. }\end{array}$ \\
\hline $\begin{array}{l}\text { Proton pump inhibitor } \\
\text { (esomeprazole, } \\
\text { pantoprazole)-clopidogrel }\end{array}$ & $12(3.4)$ & $\begin{array}{l}\text { Esomeprazole and pantoprazole may reduce serum concentrations } \\
\text { of the active metabolite(s) of clopidogrel. }\end{array}$ \\
\hline Allopurinol-warfarin & $12(3.4)$ & $\begin{array}{l}\text { Allopurinol may enhance the anticoagulant effect of vitamin } \mathrm{K} \\
\text { antagonists. }\end{array}$ \\
\hline Aspirin-warfarin & $11(3.1)$ & $\begin{array}{l}\text { Salicylates may enhance the anticoagulant effect of vitamin } \mathrm{K} \\
\text { antagonists. }\end{array}$ \\
\hline $\begin{array}{l}\text { Theophylline- } \\
\text { benzodiazepines }\end{array}$ & $11(3.1)$ & $\begin{array}{l}\text { Theophylline derivatives may diminish the therapeutic effect } \\
\text { of benzodiazepines. }\end{array}$ \\
\hline
\end{tabular}

receiving a non-selective $\beta$-blocker due to chronic $\mathrm{HF}$. This is actually implementation of guidelines because COPD is not a valid contraindication for $\beta$-blockers [12].

The number of clinically significant potential DDIs of levels C, D, and X was associated with the number of diagnoses and consequently with the number of drugs patients were receiving. Although this had been reported previously [4, 6, 17, 23], we did not see any association with the length of stay as reported by Moura et al. [1].

In our study, at least one potential DDI of clinical significance level C, D, or X at discharge was found in $94.5 \%, 30.2 \%$, and $5 \%$ of the total patient population, respectively. This prevalence is higher than presented in a study that assessed the prevalence of DDIs in patients with arterial hypertension in a community setting, which reported the prevalence of DDIs of clinical significance at level $C$ to be $83.3 \%$, level D $16.3 \%$, and level $X 0.4 \%$ [17]. One possible reason for the higher rates observed in our study lies in the comorbidity and polypharmacy of our patient population. Our cohort of patients was prescribed a median number of seven drugs at discharge, whereas the patients with arterial hypertension had a median of five [17].

The most prevalent potential DDIs of clinical significance $C$ included a combination of antihyper- tensive drugs, which may cause hypotension. The combination of more than one drug for lowering blood pressure is common and is a guideline-recommended treatment to reach target blood pressure. The combination of ACE inhibitors (or ARB), a $\beta$-blocker, and a diuretic is also recommended by ESC guidelines for treatment of chronic HF [12]. Despite the potential DDIs, the average systolic and diastolic blood pressures of the study population are still above the recommended target blood pressure. In the case of DDIs of clinical significance D, therapy modification needs to be considered. The most common drug combination that causes potential DDI of clinical significance D was a combination of $\beta$-blocker and $\alpha$ receptor antagonist (12.2\%).

There are also significant differences between the number of potential DDIs in patients with chronic HF and COPD. Chronic HF patients have more type- $C$ and type-D interactions than COPD patients, which may reflect more evidence about life-prolonging drugs established for patients with chronic HF $[11,12]$. Guidelines may also be the main reason for more DDIs in patients with concomitant chronic HF and COPD. Although this likely reflects better clinical practice, it is associated with greater risk of potentially significant DDI and should be handled accordingly.

As mentioned previously, more type-X potential DDIs were found in patients with concomitant 
Table VIII. The most common combinations of DDIs of clinical significance level $\mathrm{X}$ at hospital discharge

\begin{tabular}{|c|c|c|}
\hline Drug-drug interaction & $N(\%)$ & Description \\
\hline \multicolumn{3}{|c|}{ Total DDIs of clinical significance level $\mathrm{X}$ at discharge $n=45$} \\
\hline $\begin{array}{l}\text { Non-selective } \beta \text {-blocker- } \\
\beta_{2} \text { receptor agonist }\end{array}$ & $29(64)$ & $\begin{array}{l}\beta \text {-Blockers (nonselective) may diminish the bronchodilatory effect } \\
\text { of } \beta_{2} \text { receptor agonist. }\end{array}$ \\
\hline Rifampicin-esomeprazole & $2(4.4)$ & Rifampicin may decrease the serum concentration of esomeprazole. \\
\hline $\begin{array}{l}\alpha_{1} \text { Receptor antagonists- } \\
\alpha_{1} \text { receptor antagonists }\end{array}$ & $2(4.4)$ & $\begin{array}{l}\alpha_{1} \text { Receptor antagonists may enhance the antihypertensive effect } \\
\text { of other } \alpha_{1} \text { receptor antagonists. }\end{array}$ \\
\hline $\begin{array}{l}\text { Clarithromycin- } \beta_{2} \text { receptor } \\
\text { agonist (salmeterol) }\end{array}$ & $2(4.4)$ & $\begin{array}{l}\text { CYP3A4 inhibitors (Strong) may increase the serum concentration } \\
\text { of salmeterol. }\end{array}$ \\
\hline Escitalopram-quetiapine & $1(2.2)$ & $\begin{array}{l}\text { Highest risk QTc-prolonging agents may enhance the QTc-prolonging } \\
\text { effect of other highest risk QTc-prolonging agents. }\end{array}$ \\
\hline Haloperidol-quetiapine & $1(2.2)$ & $\begin{array}{l}\text { Moderate risk QTc-prolonging agents may enhance } \\
\text { the QTc-prolonging effect of highest risk QTc-prolonging agents. }\end{array}$ \\
\hline $\begin{array}{l}\text { Phenothiazine } \\
\text { antipsychotics-risperidone }\end{array}$ & $1(2.2)$ & $\begin{array}{l}\text { Moderate risk QTc-prolonging agents may enhance } \\
\text { the QTc-prolonging effect of highest risk QTc-prolonging agents. }\end{array}$ \\
\hline $\begin{array}{l}\text { Phenothiazine } \\
\text { antipsychotics-haloperidol }\end{array}$ & $1(2.2)$ & $\begin{array}{l}\text { Moderate risk QTc-prolonging agents may enhance } \\
\text { the QTc-prolonging effect of highest risk QTc-prolonging agents. }\end{array}$ \\
\hline Clozapine-quetiapine & $1(2.2)$ & $\begin{array}{l}\text { Moderate risk QTc-prolonging agents may enhance } \\
\text { the QTc-prolonging effect of highest risk QTc-prolonging agents. }\end{array}$ \\
\hline Haloperidol-metoclopramide & $1(2.2)$ & $\begin{array}{l}\text { Metoclopramide may enhance the adverse/toxic effect } \\
\text { of antipsychotics. }\end{array}$ \\
\hline Vitamin D-calcitriol & $1(2.2)$ & $\begin{array}{l}\text { Vitamin D analogs may enhance the adverse/toxic effect of other } \\
\text { vitamin D analogs. }\end{array}$ \\
\hline Clozapine-metoclopramide & $1(2.2)$ & $\begin{array}{l}\text { Metoclopramide may enhance the adverse/toxic effect } \\
\text { of antipsychotics. }\end{array}$ \\
\hline Amiodarone-quetiapine & $1(2.2)$ & $\begin{array}{l}\text { Moderate risk QTc-prolonging agents may enhance } \\
\text { the QTc-prolonging effect of highest risk QTc-prolonging agents. }\end{array}$ \\
\hline Omeprazole-clopidogrel & $1(2.2)$ & $\begin{array}{l}\text { Omeprazole may reduce serum concentrations of the active } \\
\text { metabolite(s) of clopidogrel. }\end{array}$ \\
\hline
\end{tabular}

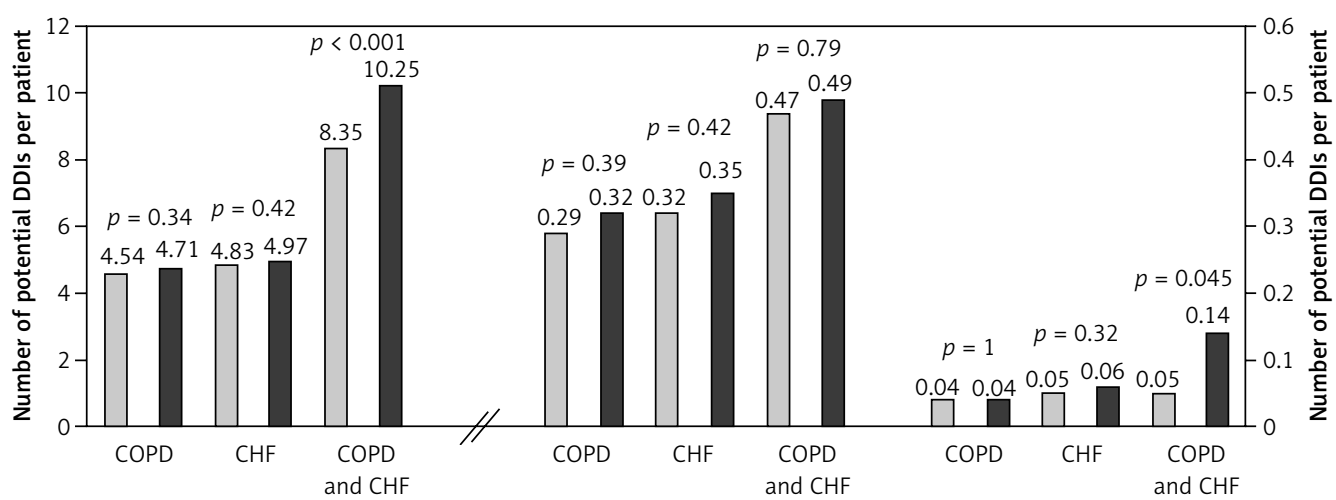

Level C DDIs

$$
\text { Level D DDIs Level X DDIs }
$$

Level of DDIs in patients

$\square$ Discharge (\%) $\quad \square$ Admission (\%)

Figure 6. Number of potential DDIs level C, D and X per patient on admission and on discharge in patients with COPD only, chronic HF (CHF) only and concomitant COPD and chronic HF (CHF)

chronic HF and COPD and most of these were between a non-selective $\beta$-blocker (carvedilol) and a $\beta$, receptor agonist (64\%). In clinical practice, COPD is not a contraindication for $\beta$-blocker use, and abundant evidence supports $\beta$-blocker use in patients with chronic HF. Furthermore, several studies have demonstrated that cardioselective $\beta$-blockers have fewer pulmonary side effects than non-selective ones [24-28] and should be the preferred agent of choice in these patients [12]. However, a study that assessed that tolerability of carvedilol in patients with chronic HF 
Table IX. Associations between number of potential DDIs of significance level C, D, and X and number of diagnoses, number of drugs, and length of hospital stay

\begin{tabular}{|lcc|}
\hline Variable & Pearson's coefficient $\left(r^{2}\right)$ & Value of $p$ \\
\hline Association between number of drugs and number of potential DDIs of significance level: & 0.322 & $<0.001$ \\
\hline C & 0.212 & 0.001 \\
\hline X & 0.013 & $<01$ \\
\hline Association between number of diagnoses and number of potential DDIs of significance level: & 0.148 \\
\hline C & 0.148 & $<0.001$ \\
\hline D & 0.035 & $<0.001$ \\
\hline X & 0.001 \\
\hline Association between length of hospital stay and number of potential DDIs of significance level: & 0.006 \\
\hline C & 0.000 & 0.032 \\
\hline D & 0.000 & 0.781 \\
\hline
\end{tabular}

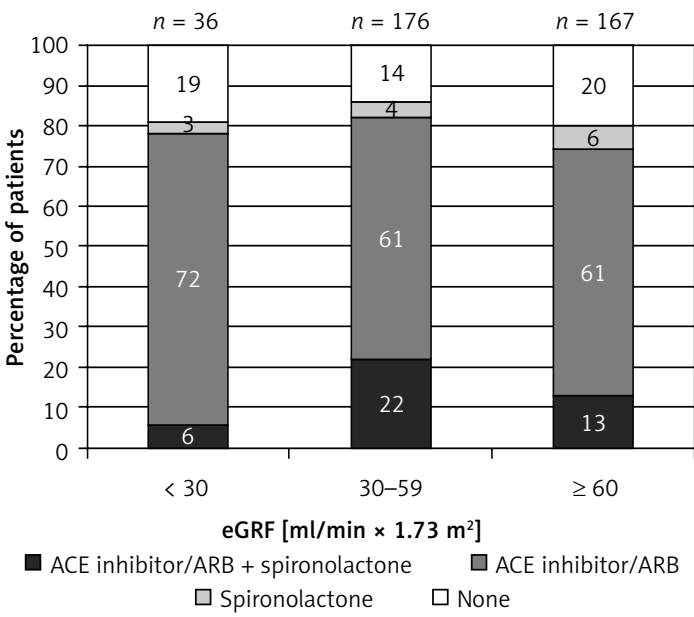

Figure 7. Proportion of patients with chronic HF receiving ACE inhibitor/ARB and/or spironolactone according to the estimated glomerular filtration rate (eGRF)

and concomitant COPD showed that peak expiratory flow rate measured before and $2 \mathrm{~h}$ after administration of carvedilol increased by $17 \%$ $(p=0.04)$. This effect might be due to decreased airflow obstruction, peribronchial fluid, and filling pressures on improved cardiac function [24]. This is a small study, but it raises the question of whether this combination is indeed contraindicated. Furthermore, it should be mentioned that the beneficial effects of $\beta$-blockers extend beyond the cardiac system because they have beneficial effects on the body and glucose metabolism [29-31].

Antipsychotic drugs are commonly involved in potential DDIs of significance level X. Quetiapine, clozapine, haloperidol, risperidone, and phenothiazine antipsychotics may enhance the QTc-prolonging effect of other drugs or each other if used together. This is due to altered activity of cytochrome P450 activity, and consequently plasma concentrations of co-administered drugs may be increased or decreased [32]. In our study, only a small proportion of patients were prescribed these drugs. Although not frequent, these combinations should be avoided whenever possible.

The use of the DDI database provides only a general estimate of clinical importance, which needs to be tailored to the individual patient, particularly to laboratory parameters and comorbidities. Renal (dys)function is a major determinant of pharmacological treatment in patients with chronic disease [33]. Clinicians must be particularly cautious with spironolactone, which has been associated with increased prevalence of hyperkalemia and increased mortality [34]. Generally, aldosterone antagonists should be withheld in patients with $\mathrm{eGFR}<30 \mathrm{ml} /\left(\min \times 1.73 \mathrm{~m}^{2}\right)$ and used only under close monitoring if eGFR is between 31 and $60 \mathrm{ml} /\left(\min \times 1.73 \mathrm{~m}^{2}\right)$ [33]. Clinical practice across Europe [20], however, is not following this advice and our study reports similar results. In two (3\%) patients with eGFR $<30 \mathrm{ml} /(\min \times$ $1.73 \mathrm{~m}^{2}$ ), we should change combination therapy to monotherapy due to an increased risk of arrhythmia, and in 38 (22\%) patients regular checks of serum electrolytes and markers of renal function should be advised in specialized outpatient settings. However, $72 \%$ of patients with eGFR $<30$ $\mathrm{ml} /\left(\mathrm{min} \times 1.73 \mathrm{~m}^{2}\right)$ were prescribed only an ACE inhibitor or ARB and $3 \%$ only spironolactone. Surprisingly, in chronic HF patients with normal renal function, where the combination of these drugs 
would be preferred, this combination was found only in $13 \%$ of patients.

The main limitations of our study were its retrospective design, diagnoses from discharge letters, and incomplete information on the medication prescribed. However, the prevalence of missing data is still lower than observed in other studies [23]. Another limitation is the evaluation of potential DDIs with software, which provides only a general estimate of clinical significance. Based on previous research, this is the most frequently used software and provides information with the highest sensitivity, although it detects potential DDIs that may not be of high clinical significance [15]. All DDIs should therefore be interpreted individually; from available data, we have adjusted the Lexi DDI for renin-angiotensin-aldosterone modulators according to patient renal function. The DDIs are also influenced by daily doses and patient characteristics (e.g. renal function, blood pressure, heart rate, etc), and we controlled for this only partially (Figure 7). The electronic systems used for identification of potential DDIs in this study and in clinical practice do not consider daily dose; per study design we therefore did not control for daily dose, which may not be so relevant for identification of potential DDIs but certainly is crucial for evaluation of clinical relevance, which however was beyond the scope of this study.

In conclusion, there is a high prevalence of DDIs in patients with chronic HF and COPD. This appears to be due to the high number of medications required by comorbidity. Some of these could be avoided, but the majority of them likely reflect better guideline implementation rather than poor clinical practice. Clinical significance, however, should be interpreted individually before any actions are taken. An adjustment for renal function using eGFR can stratify patients for the risk of worsening renal function and hyperkalemia risk. Previous experience about decisions in clinical practice, particularly for the use of $\beta$-blockers, show that clinicians are reluctant to withdraw life-saving medication and prefer to either delay or stop up-titration $[13,35]$. The literature about safe use in patients with concomitant chronic HF and COPD is steadily growing and supports the use of a cardioselective $\beta$-blocker with fewer side effects and no significant change in lung function $[25,26]$. This is particularly important because $\beta$-blockers have many ancillary effects, including glucose and body metabolism $[29,30]$, which could prevent body wasting and poor prognosis [36].

Discussions about pharmacological management, DDIs, and the risk of side effects should always include patients and their caregivers. Implementation of non-pharmacological advice and close self-management $[12,34]$ with reporting to medical professionals is crucial for early recognition of evolving complications and can prevent irreversible consequences. Ideally, patients should be managed in specialized outpatient settings at least during their vulnerable periods (e.g., after hospitalization and during medication regimen modification) because this appears to improve patient knowledge and prognosis [37-39].

\section{Acknowledgments}

The present study was not funded. None of the authors have any conflicts of interest directly relevant to the content of this study.

\section{References}

1. Moura C, Acurcio F, Belo N. Drug-drug interactions associated with length of stay and cost of hospitalization. J Pharm Pharmaceut Sci 2009; 12: 266-72.

2. Piromohamed M, James S, Meakin S, et al. Adverse drug reactions as cause of admission to hospital: prospective analysis of 18820 patients. BMJ 2004; 329: 15-9.

3. Juurlink DM, Mamdani M, Kopp A, et al. Drug-drug interactions among elderly patients hospitalized for drug toxicity. JAMA 2003; 289: 1652-8.

4. Björkman KI, Fastborn J, Schmidt IK, et al. Drug-drug interactions in elderly. Ann Pharmacother 2002; 36: 1675-81.

5. Gallagher P, Barry P, O'Mahony D. Inappropriate prescribing in the elderly. J Clin Pharm Ther 2007; 32: 113-21.

6. Radošević N, Gantumur M, Vlahović-Palčevski V. Potentially inappropriate prescribing to hospitalised patients. Pharmacoepidemiol Drug Saf 2008; 17: 733-7.

7. Vonbach P, Dubied A, Krähenbühl S, et al. Prevalence of drug-drug interactions at a hospital entry and during hospital stay of patients in internal medicine. Eur J Int Med 2008; 19: 413-20.

8. Straubhaar B, Krähenbühl S, Schlienger RG. The prevalence of potential drug-drug interactions in patients with heart failure at hospital discharge. Drug Saf 2006; 29: 79-90.

9. Alderman CP. Patient-oriented strategies for the prevention of drug interactions. Drug Saf 2000; 22: 103-9.

10. Goldberg RM, Mabee J, Chan L, et al. Drug-drug and drug-disease interactions in ED: analysis of high-risk population. Am J Emerg Med 1996; 14: 447-50.

11. Rabe KF, Hurd S, Anzueto A, et al. Global strategy for the diagnosis, management, and prevention of chronic obstructive pulmonary disease: GOLD Executive Summary. Am J Respir Crit Care Med 2007; 176: 532-55.

12. McMurray JJV, Adamopoulos S, Anker SD, et al. ESC Guidelines for the diagnosis and treatment of acute and chronic heart failure 2012. Eur J Heart Fail 2012; 14: 803-69.

13. Düngen HD, Apostolović $S$, Inkrot $S$, et al. Titration to target dose of bisoprolol vs. carvedilol in elderly patients with heart failure: the CIBIS-ELD trial. Eur J Heart Fail 2011; 13: 670-80.

14. Egger SS, Drewe J, Schlienger RG. Potential drug-drug interactions in the medication of medical patients at hospital discharge. Eur J Clin Pharmacol 2003; 58: 773-8.

15. Vonbach P, Dubied A, Krähenbühl S, et al. Evaluation of frequently used drug interaction screening programs. Pharm World Sci 2008; 30: 367-74. 
16. Smithburger PL, Kane-Gill SL, Seybert AL. Drug-drug interactions in cardiac and cardiothoracic intensive care units. Drug Saf 2010; 33: 879-88.

17. Bacic-Vrca V, Marusic S, Erdeljec V, et al. The incidence of potential drug-drug interactions in elderly patients with arterial hypertension. Pharm World Sci 2010; 32: 815-21.

18. Smithburger PL, Kane-Gill SL, Benedict NJ, et al. Grading the severity of drug-drug interactions in the intensive care unit: a comparison between clinician assessment and proprietary database severity rankings. Ann Pharmacother 2010; 44: 1718-24.

19. Levey AS, Bosch JP, Lewis JB, et al. A more accurate method to estimate glomerular filtration rate from serum creatinine: a new prediction equation. Modification of Diet in Renal Disease Study Group. Ann Intern Med 1999; 130: 461-70.

20. Lainščak M, Cleland JGF, Lenzen MJ, et al. International variations in the treatment and co-morbidity of left ventricular systolic dysfunction: data from the EuroHeart Failure Survey. Eur J Heart Fail 2007; 9: 292-9.

21. Sarc I, Jeric T, Ziherl K, et al. Adherence to treatment guidelines and long-term survival in hospitalized patients with chronic obstructive pulmonary disease. J Eval Clin Pract 2011; 17: 737-43.

22. Lainscak M, Majc Hodoscek M, Dungen HD, et al. The burden of chronic obstructive pulmonary disease in patients hospitalized with heart failure. Wien Klin Wochenschr 2009; 121: 309-13.

23. Fotker N, Mozina M, Brvar M. Potential drug-drug interactions and admissions due to drug-drug interactions in patients treated in medical departments. Wien Klin Wochenschr 2010; 122: 81-8.

24. Kotlyar E, Keogh AM, Macdonald PS, et al. Tolerability of carvedilol in patients with heart failure and concomitant chronic obstructive pulmonary disease and asthma. J Heart Lung Transpl 2002; 21: 1290-5.

25. Jabbour A, Macdonald PS, Keogh AM, et al. Differences between beta-blockers in patients with chronic heart failure and chronic obstructive pulmonary disease. Am J Coll Cardiol 2010; 55: 1780-7.

26. Lainscak M, Podbregar M, Kovacic D, et al. Differences between bisoprolol and carvedilol in patients with chronic heart failure and chronic obstructive pulmonary disease: a randomized trial. Respir Med 2011; 105 (Suppl. 1): S44-9.

27. Antczak A, Ciebiata M, Pietras T, et al. Exhaled eicosanoids and biomarkers of oxidative stress in exacerbation of chronic obstructive pulmonary disease. Arch Med Sci 2012; 8: 277-85.

28. Wozniak K, Sleszycka J, Safinowska A, et al. Systemic inflammation in peripheral arterial disease with or without coexistent chronic obstructive pulmonary disease: analysis of selected markers. Arch Med Sci 2012; 8: 477-83.

29. Kovačič D, Marinšek M, Gobec L, et al. Effect of selective and non-selective beta-blockers on body weight, insulin resistance and leptin concentration in chronic heart failure. Clin Res Cardiol 2008; 97: 24-31.

30. Lainscak M, Keber I, Anker SD. Body composition changes in patients with systolic heart failure treated with beta blockers: a pilot study. Int J Cardiol 2006; 106: 319-22

31. Wojticzak-Soska K, Pietrucha T, Sakowicz A, et al. Soluble ST2 protein in chronic heart failure is independent of traditional factors. Arch Med Sci 2013; 9: 21-6.

32. Spina E, de Leon J. Metabolic drug interaction with newer antipsychotics: a comparative review. Basic Clin Pharmacol Toxicol 2007; 100: 4-22.
33. Schlipak MG. Pharmacotherapy for heart failure in patients with renal insufficiency. Ann Int Med 2003; 138 917-24.

34. Juurlink DN, Mamdani MM, Lee DS, et al. Rates of hyperkalemia after publication of the randomized aldactone evaluation study. NEJM 2004; 351: 543-51.

35. Lainscak M, Moullet C, Schön N, et al. Treatment of chronic heart failure with carvedilol in daily practice: the SATELLITE survey experience. Int J Cardiol 2007; 122: 149-55.

36. Farkas J, von Haehling S, Kalantar-Zadeh K, et al. Cachexia as a major public health problem: frequent, costly, and deadly. J Cachexia Sarcopenia Muscle 2013; 4 173-8.

37. Lainscak M, Blue L, Clark AC, et al. Self-management of heart failure: practical recommendations from patient care committee of the heart failure association of the European Society of Cardiology. Eur J Heart Fail 2011; 13: $115-26$.

38. Gonseth J, Guallar-Castillon P, Banegas JR, et al. The effectiveness of disease management programs in reducing re-admission in older patients with heart failure: a systematic review and meta-analysis of published reports. Eur Heart J 2004; 25: 1570-95.

39. Lainščak M, Keber I. Patients' knowledge and beta blocker treatment improve prognosis of patients from a heart failure clinic. Eur J Heart Fail 2006; 8: 187-90. 